\title{
Community paediatrics and change
}

\section{E Curtis, T Waterston}

\section{What is the future of community paediatrics?}

S hould community paediatrics continue as a separate specialty, as it has been since the publication of the Court Report, ${ }^{1}$ or should it merge with general paediatrics, or with primary care? The Royal College of Paediatrics and Child Health has taken a lead role in the debate on the future configuration of child health services and training and on the future shape of community child health. Two documents, Looking ahead: paediatrics and child health-the next 10 years, ${ }^{2}$ and the review of community paediatrics, Strengthening the care of children in the community, ${ }^{3}$ have been published to facilitate and stimulate discussion. There are other important factors which will hasten change in community paediatrics: a stated government commitment to eradicate child poverty, the long awaited decision to develop a National Service Framework for children, the establishment of Primary Care Trusts, and the recent Bristol Royal Infirmary Inquiry. As a result, all child health services will be expected to undergo change and we would urge that this be in the direction of integrated services and a greater community orientation.

Over the past three decades the whole context in which we operate as paediatricians has changed enormously. We are much better able to investigate and treat childhood illnesses, but at the same time parents' expectations are much higher. The government has identified new priorities in the NHS Plan-children looked after, adoption, mental health, and nutrition. ${ }^{4}$ There is the increasing evidence of the poor health of children looked after (in local authority care) and hence the need to devote more paediatric time to their assessment and support. ${ }^{5}$ There is government concern that there should be a move towards coordinated service planning for vulnerable children and young people; this will clearly have important implications for future practice for all paediatricians, especially those who have a role in the community. ${ }^{6}$ There is an increasing workload in mental health, disability and chronic illness, high risk behaviour (drug and alcohol abuse, smoking, earlier sexual intercourse), and the impact of deepening inequalities in child health. The UK is currently ranked fourth bottom of 23 industrialised countries in the proportion of children living in relative poverty; this has a huge impact on their health. ${ }^{7}$ There is a current epidemic of emotional and behavioural problems in UK children which is impacting adversely on educational attainment, on self esteem, and on the health and wellbeing of families generally. Child and adolescent mental health services are insufficient to handle these problems and many paediatricians are developing an interest in this field and improving their skills. Can we manage the increased workload, along with the need to organise community based provision and parenting support that comes with it?

\section{"Partnership with parents is not an easy goal to reach"}

The Bristol Royal Hospital Inquiry highlights the fact that parents wish to be treated with respect and to be included in the process of caring for their children. ${ }^{8}$ Partnership with parents has always been a goal of community paediatricians, as well as of many hospital based paediatricians, but it is not an easy goal to reach. Sharing all correspondence with parents is one simple method of working in partnership, ${ }^{9}$ and is a recommendation of the NHS Plan. Yet our impression is that it is still the exception for hospital paediatricians to copy letters to parents.

Paediatric trainees do not appear to rank community paediatrics highly as a career choice and there are consultant posts unfilled. Conversation with trainees reveal the following reasons for this apparent disinterest: a desire to be an expert (which it is felt will not be fulfilled by general or community paediatrics); outdated views of what community paediatrics involves (routine school entry medicals and isolated working patterns); absence of a strong academic record in community paediatrics; and an impression of reluctance by community paediatricians to be involved in acute care.

So, what is the current focus of community paediatricians? We work in a diverse clinical specialty which defies a single job description as most posts have evolved in response to local needs. While there are many "general" consultant community paediatricians, there are a growing number who consider themselves to be specialists in a specific area, for example, neurodisability, forensic paediatrics, behavioural paediatrics, and public health. Given its diversity it is probably not surprising that there are few data available on the nature of community paediatric practice. We carried out a postal survey of 128 consultant community paediatricians in 1998, asking about their practice and their views about community paediatrics. ${ }^{10}$ Ninety seven $(76 \%)$ replied. We also surveyed 100 hospital based paediatricians on their views on community paediatrics; 48 replied. Many community paediatricians commented on a lack of contact with hospital based colleagues and feelings of isolation. Thirty one per cent of hospital paediatricians and $79 \%$ of community paediatricians considered that hospital based paediatricians had a poor understanding of community child health. Just one third of the 97 who responded were involved in acute and general paediatrics and only half had equal access to hospital beds, facilities, and junior staff. Most identified an area of special interest; for 34\% this was neurodisability and for $30 \%$ child protection. There was a wide range of other special interests reported (public health $(7 \%)$, mental health $(6 \%)$, educational medicine $(5 \%)$, looked after children and adolescent health $(<5 \%))$. Non-clinical tasks occupied between a quarter and a half of their time and just $20 \%$ felt this was excessive. One third were single handed, working as the only consultant community paediatrician in their district. Many commented on the need for more and improved research within community paediatrics to provide an evidence base for practice. This survey revealed that there is still a disturbing gulf between hospital based and community paediatricians; we recommend that any future policy proposals should work to eradicate this and, we hope, bring all general paediatricians together around a common philosophy.

\section{"Community paediatrics is a philosophy of delivery of child health care"}

We believe that community paediatrics is not a specialty as such but a philosophy of delivery of child health care with the following principles: high accessibility; holistic vision; close working with parents; interagency care and teamwork; advocacy directed at the needs of all children; and above all a preventive orientation. One might argue that these should be applicable to the work of all general paediatricians. The challenge and the job satisfaction come from combining short and long term care in general paediatrics with multiagency work to tackle the determinants of 
health (see box 1 for examples). This is what makes it different from hospital based paediatrics as it is presently organised. We would like to see all paediatricians embrace these principles. In the future, community paediatricians will be competent in general (acute) and community paediatrics. Community paediatricians highlight feelings of isolation and report that poor communication with hospital based colleagues is common. A combined service with both community and hospital paediatricians involved in the delivery of acute and community services is one obvious solution. Yet, among many community paediatricians, there is reluctance to participate in acute rotas for a number of reasons. There is concern about maintenance of skills and the fact that time committed to this would encroach on their time for community based work.

Box 1 Examples of community paediatric initiatives

(1) Young People's Health Project. This project was funded by the Northumberland Health Authority between 1996 and 1998. The project was managed by a consultant community paediatrician and employed a full time coordinator. The health sessions were staffed by youth workers as well as health staff, and included a sexual health service. The project provided an opportunity for young people to work with professionals to develop effective and user friendly models of health care and to improve their access to the existing range of services. "

(2) A comprehensive school in Newcastle, given a new start, brought together health, education and social services in an effort to identify young people in difficulty, to share interagency knowledge and experience, and to try to prevent school failure by early intervention. The bringing together of agencies to one forum was found to be more efficient by all agencies and brought about much closer co-working.

(3) Multiagency training in the management of preschool behaviour problems was organised for social workers, nursery nurses, health visitors, school nurses, and paediatricians in cognitive behaviour therapy so that all would have a common basis for management.

(4) The development of an asthma and epilepsy policy for use in schools, including training of staff in recognition and management, was undertaken to ensure that children with these conditions could remain in school, take their medication, and feel supported, even in severe cases.
For those who are not currently involved in acute paediatrics there is an issue of regaining skills in this area.

These are tough issues which need to be confronted and discussed openly. In the future, we would hope to see all general paediatricians working together as part of a multiskilled team providing a holistic paediatric service to a district. Many would work in hospitals as well as the community, and many "hospital" colleagues would work outside hospitals and engage in multiagency work. The skills of community paediatricians will be essential for all future paediatricians. Their understanding of multiagency working, essential to improving services for children and their families, places general/community paediatricians in a unique position to bring about real change and improve children's lives. This will entail putting children's needs before professionals', being prepared and able to attend multiagency meetings, and knowing the names of head teachers and school nurses as well as physiotherapists and speech therapists in a locality. The location of community paediatric services will need to be addressed. Some currently reside in Primary Care Trusts and others in integrated (community and hospital) acute trusts. The experience of community paediatric staff in different locations, and the impact this has on their delivery of service, will need to be reviewed with time.

Community and hospital paediatricians need to embrace the opportunity to shape future ways of working together for the benefit of children and their families. The following are areas that must be considered in future planning:

- Primary care commissioning/ providing will become established and the relationship between paediatricians and primary care teams will be of great importance. There will need to be support of primary care teams with outreach and a clear referral pathway for both physical and mental health problems.

- There will need to be a multidisciplinary approach to secondary care provision which will include paediatricians, nurses, professions allied to medicine (PAMs), social workers, and psychologists.

- Hospital and community paediatricians should work in the same team serving a defined population group. They should have complementary skills in order to provide for the health needs of this population.

- There will need to be flexibility in relation to acute on-call. Only community paediatricians whose acute skills have been maintained should be involved in acute on-call rotas. Consideration must be given to protecting
Box 2 American Academy of Paediatrics-definition of community paediatrics ${ }^{12}$

- A perspective that enlarges the paediatrician's focus from one child to all children in the community.

- A recognition that family, educational, social, cultural, spiritual, economic, environmental, and political forces act favourably or unfavourably, but always significantly, on the health of children.

- A synthesis of clinical practice and public health principles directed towards providing health care to a given child and promoting the health of all children within the context of the family, school, and community.

- A commitment to utilise a community's resources in collaboration with other professionals, agencies, and parents to achieve optimal accessibility, appropriateness, and quality of services for all children and to advocate especially for those who lack access to care because of social or economic conditions or their special health care needs.

time for community based work. Some consultant posts (at least one per district) should be designed to be full time in the community without acute on-call commitments.

- There needs to be high quality training in community paediatrics for all paediatric trainees. This should provide generic skills for all future paediatricians, which should include mental health and public health skills. However, within community paediatrics (as within general paediatrics) there are specialist areas for which more specific training is required, and trainees should be able to opt into this training during their later SpR years.

- Each district should specify the organisational responsibilities, including public health responsibilities, which should be shared among the ("general") consultant paediatricians serving that district.

- There is a need to continue to strengthen the academic base in community paediatrics.

- The title "community paediatrician" remains valid until there is a shared understanding and agreement about joint working between community and hospital paediatricians.

- The description of community paediatrics used by the American Academy of Pediatrics is valuable (box 2) and should be understood by all paediatricians in the UK. 


\section{Authors' affiliations}

E Curtis, T Waterston, Community Paediatrics, Newcastle General Hospital, Westgate Road,

Newcastle upon Tyne NE4 6BE, UK

Correspondence to: Dr E Curtis, Community Paediatrics, Newcastle General Hospital,

Westgate Road, Newcastle upon Tyne

NE4 6BE, UK; emma.curtis@ncht.northy.nhs.uk

\section{REFERENCES}

1 Court SDM. Fit for the future. The report of the Committee on Child Health Services. London: HMSO, 1976.
2 Hall D. Looking ahead: paediatrics and child health - the next ten years. Discussion paper. London: RCPCH, June 2001.

3 Craft A, McClellan N, Sibert J. Strengthening the care of children in the community. $A$ review of community child health. Discussion paper. London: RCPCH, June 2001

4 Department of Health. The NHS Plan, a plan for investment, a plan for reform. London HMSO, 2000

5 Polnay L, Ward H. Promoting the health of looked after children. BM 2000;320:661-2.

6 Social Services Inspectorate. Co-ordinated service planning for vulnerable children and young people in England. London: $\mathrm{HMSO}$ 2001 .

7 UNICEF. Child poverty in rich nations. Florence: UNICEF, ICDC, 2000
8 The Bristol Royal Infirmary Inquiry. London: HMSO, July 2001

9 Waterston T, San Lazaro C. Sending parents outpatient letters about their children: parents and general practitioners' views. Qual Health Care 1994:3:142-6.

10 Curtis E, Waterston T. Survey of hospital and community paediatricians. Unpublished data. 1998

11 McNulty A, Turner G. "Not just a phase we're going through..." Final Report of Northumberland Young People's Health Project 1996-1998. Northumberland, 1998.

12 American Academy of Pediatrics, Committee on Community Child Health Services. The paediatrician's role in community paediatrics. Pediatrics 1999:103:1304-6.

\title{
POSTCARD FROM DOWN UNDER
}

\author{
Buying the didgeridoo from Uncle
}

$\mathrm{D}$ eep in the outback, at a small town clinic, I got to speaking with Uncle who told me that he made the odd didgeridoo and boomerang. I arranged to meet with him at his house in the next hour or so. In these parts, doctors are driven the shortest distances in air conditioned cars, and I was surprised an hour later to arrive at his house, just a few hundred metres away, at the same time as him. He'd been walking his slow pace, stopping to pass the time of day with everyone he met.

I was invited into his ramshackle house, and felt a little nervous about the five or six men sitting and leaning about outside, clearly the worse for wear at midday from the effects of beer. Uncle himself, I'd been told, was not one for the grog though. The house was on stilts, and I was guided through to his tiny room with large cupboard. The room had a child-like "Uncle, Private Keep Out" on the door in felt tip, and inside had a thin, centimetre thick mattress and a number of tools on the floor. From the chaos in the cupboard, he bought out the didgeridoo, more than a metre long, simple and beautiful. He'd been into the bush to select the wood, which has to have been hollowed out by termites, before working it into better shape and then painting it. The base colour was the deep red of the dirt that is the outback, the desert. At each end, and slightly more than halfway down were black bands with wavy lines and dots in yellow, white, and green. The price was high, but not as high as in a city centre art gallery, where the middle men take more than their share.

During our conversation, a drunk man (one of his sons) began to ask me about his heart pills. I took my habitual refuge; "I'm sorry, I only know about medicine in children, not adults." It required several repetitions to establish this fact, to the point where other

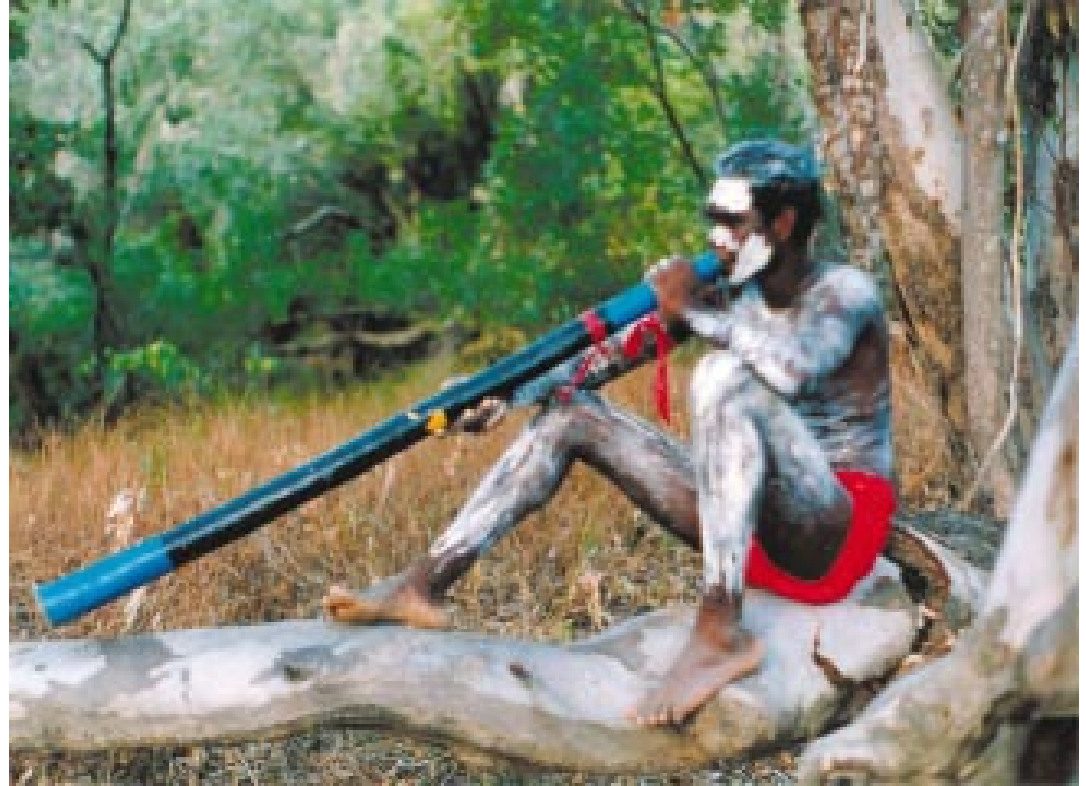

Figure 1 Reproduced with kind permission from The Didjshop (http://didjshop.com).

onlookers were reiterating my protest, and I was waving my hand at around waist level to demonstrate how small he had to be before I could give him advice.

The banknotes I gave Uncle disappeared very quickly -into somewhere about his person or into his locked room-and all sides seemed pleased with the bargain. I felt sure that no one else would see that cash until Uncle himself was good and ready to spend it I took the didgeridoo and said my goodbyes.

As I took the bold step of walking myself the 250 metres back to the clinic, didgeridoo under my arm, I felt very self conscious. Did I appear like some arrogant tourist? Some sort of fool, easily parted from his money? Had been taken in by a pretty story and the label "genuine"? Was I plundering cultural artefacts? Was I putting money into the hands of someone who would convert it in some way into cheap alcohol? Or, was I just a foreign doctor, pleased at having bought a real work of art from a real human being, cutting out the city centre middle man, and destined to derive years of happy memories at the sight of such a lovely thing ?

I D Wacogne

Chief Resident, Royal Children's Hospital, Brisbane 